\title{
Dissipation Loop for Shoot-Through Faults in HVDC Converter Cells
}

\author{
Keijo Jacobs, Staffan Norrga, Hans-Peter Nee \\ KTH Royal Institute of Technology, EECS, Stockholm, Sweden \\ E-mail: keijoj@kth.se
}

\begin{abstract}
Converter cells for HVDC applications store large amounts of energy. This energy might be dissipated in a very short time in case of a shoot-through fault. Measures to avoid shoot-through or handle the extreme currents during a fault and prevent damage from neighboring components are essential to ensure a continued operation of the converter. With future high-voltage silicon carbide semiconductors, cell voltages can be increased leading to higher stored energy per cell. In cells with thyristor-based semiconductors, e.g. IGCTs, a di/dt reactor may have to be employed. This paper presents a method to handle the dissipated energy during shoot-through which makes use of the inherently needed di/dt reactor. The majority of the stored energy in the cell can be dissipated in a dedicated discharge loop formed by the reactor and an antiparallel bypass thyristor. After diverting the fault current into the dissipation loop, there is no current through any other component of the cell.
\end{abstract}

Keywords-Fault currents, short-circuit currents, HVDC transmission, modular multilevel converters, electronic packaging thermal management

\section{INTRODUCTION}

High-voltage direct-current (HVDC) converters are built to operate for several decades. A redundancy is needed in order to reliably operate the converter after parts have failed. During maintenance, the failed parts can be repaired or exchanged. In modular multilevel converters (MMCs), which employ cascaded cells, the required redundancy is realized by implementing more converter cells than initially needed. There are concepts using hot-swapping of converter cells [1]; however, they have not been implemented for HVDC converters.

One of the most serious faults in an MMC is the internal cell shoot-through fault. If one power semiconductor of a converter cell fails, the cell capacitor may be short-circuited, resulting in a very fast discharge of the stored energy. The consequences of such a fault are highly dependent on the failure mode of the semiconductor packaging. Insulated-gate bipolar transistors (IGBT) packaged in wire-bonded modules (WBMs) have an open-circuit failure mode, i.e. the bond wires melt in an overcurrent event. The resulting arcing causes the silicone gel in the package to evaporate, leading to an explosion. Therefore, converter cells employing WBM IGBTs require an explosion-proof housing [2] and have to be bypassed as fast as possible at the terminals. Integrated gate-commutated thyristors (IGCT) in presspack housing have a stable short-circuit failure mode (SCFM). A failed device will melt locally between the two pressured plates and form a low-resistive short-circuit [3]. Additionally, compared to WBM IGBTs, IGCTs are predicted to increase reliability, decrease losses, and offer higher power capability in MMCs [4], [5]. An implementation is presented in [6].

Still, in case of a shoot-through fault, measures have to be taken to protect the components in the cell and in the rest of the converter. The dissipated energy may heat up components to a critical temperature. Furthermore, the forces created by the high surge currents may damage the mechanical construction. In the worst case, the current path is interrupted, resulting in arcing. The effects of the fault should in all cases be contained within the cell, so that damage to neighboring converter cells is avoided. Hence, a strategy to handle these faults is essential for the reliable operation of HVDC converters.

There are measures to reduce the risk of shoot-through by series connecting several semiconductors to a stack, forming a single switch. A redundancy is introduced by rating the series connection for a higher voltage than the operation voltage of the cell. If one semiconductor in the stack fails, the others can still support the necessary voltage. A stable SCFM of the semiconductors is a requirement for this method. The series connection can also be incorporated into a new topology, for example the double module presented in [7]. However, the redundancy in terms of series connected semiconductors comes at the cost of increased conduction losses and complexity. A cell topology reducing conduction losses while having an increased shoot-through protection is presented in [8]. The full-bridge arrangement has two paths for the current during the bypass state of the cell, reducing the effective on-state resistance. This is made possible by an additional switch in series to the capacitor, which also introduces an additional redundance.

For the future, there are several possible developments leading to higher stored energy (therefore more difficult shoot-through fault handling) in converter cells:

- The maximum cell voltage is limited by today's semiconductor voltage rating (with the exception of cells employing series-connected devices). Future silicon carbide (SiC) power semiconductors may be designed to withstand substantially higher breakdown voltages than current silicon (Si) devices. Increased cell voltage reduces the amount of required cells per arm, thus also reducing converter complexity and possibly volume [9]. 
- High-voltage cells can be utilized to increase the dc-link voltage. This allows for higher transmission power, or alternatively, for reduced current and losses.

- In order to achieve more transmission power it can be decided to increase the rated current, in which case a higher cell capacitance is needed to maintain a low cell voltage ripple.

In this paper, shoot-through faults for several cell designs are analyzed, and a discharge loop (DL) for handling those faults is presented. Section II presents the characteristics and implications of a shoot-through fault for cells with only parasitic inductance and for cells with a dedicated inductor. Section III describes the DL as a method to handle shoot-through faults. In Section IV, it is analyzed how much energy is dissipated in the halfbridge. Estimations are carried out for the temperature increase of the semiconductors. Conclusions are drawn in Section V.

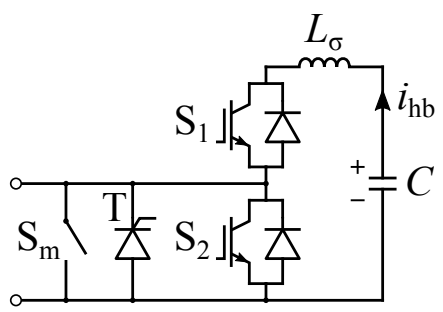

(a)

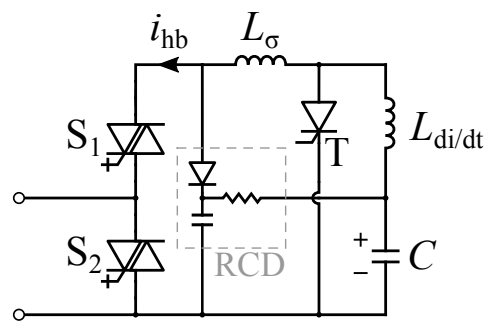

(b)

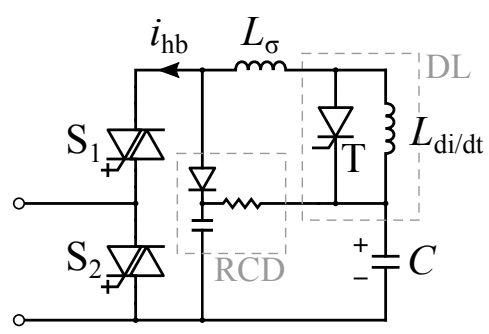

(c)

Fig. 1. Half-bridge cell employing IGBTs (a), IGCTs with bypass thyristor (b), and IGCTs with proposed discharge loop (c).

\section{UNCONTROLLED SHOOT-THROUGH FAULTS}

A shoot-through fault occurs if a low resistive path is provided between the positive and the negative terminal of the cell capacitor. This might happen if one of the switches in the half-bridge fails. The capacitor then discharges through the half-bridge with the characteristic of a damped oscillation. The parameters determining the shape of the oscillation are:

1) cell capacitance $C$, which is determined by the energy storage requirements of the converter;

2) inductance, which can be parasitic stray inductance of the busbars $L_{\sigma}$ or a dedicated inductor $L_{\text {di } / \text { dt }}$;

3) resistance, determined by the on-state resistance of the semiconductor devices $R_{\mathrm{on}}$, the busbars $R_{\text {bus }}$, and the ESR of the cell capacitor.

As depicted in Fig. 1 (a), a standard half-bridge cell with IGBTs has only parasitic inductance $L_{\sigma}$. An IGCT implementation (Fig. 1 (b)) requires a di/dt limiting reactor $L_{\mathrm{di} / \mathrm{dt}}$ in order to limit turn-on currents through the semiconductors. Without limiting $\mathrm{di} / \mathrm{dt}$, the current does not have enough time to spread across the wafer plane, leading to current filamentation. The associated heat dissipation at a certain spot might cause the device to melt locally. Furthermore, an RCD circuit has to be added to discharge $L_{\mathrm{di}} / \mathrm{dt}$. This becomes necessary since there is no current path when a positive current through the IGCT $S_{1}$ is turned off. A bypass thyristor is added across the half-bridge.

With the circuit shown in Fig. 1 (b), the maximum short-circuit current through the IGCT cell is limited by $L_{\mathrm{di} / \mathrm{dt}}$. Hence, the reactor is an inherent protection against high surge currents. This is favourable from a mechanical perspective, since mechanical forces scale quadratically with current. The uncontrolled short-circuit current during a shoot-through fault flows through the half-bridge and can be analytically expressed by solving the differential equation for the 2 nd order system formed by R, L, and C.

$$
i_{\mathrm{sc}}(t)=\frac{V_{\mathrm{C}}}{L \omega_{\mathrm{o}}} e^{-t / \tau} \sin \left(\omega_{\mathrm{o}} t\right),
$$

where the parameters $\omega_{\mathrm{o}}, L, R$, and $\tau$ are given by

$$
\begin{gathered}
\omega_{\mathrm{o}}=\sqrt{\frac{1}{L C}-\frac{R^{2}}{4 L^{2}}} \\
L=L_{\mathrm{di} / \mathrm{dt}}+L_{\sigma} \\
R=R_{\text {bus }}+\mathrm{ESR}+R_{\text {semicond }} \\
\tau=\frac{2 L}{R} .
\end{gathered}
$$

The peak current can be calculated as

$$
i_{\mathrm{sc}, \max }=\frac{V_{\mathrm{C}}}{L \omega_{\mathrm{o}}} e^{-\frac{\arctan \left(\omega_{\mathrm{o}} \tau\right)}{\omega_{\mathrm{o}} \tau}} \sin \left[\arctan \left(\omega_{\mathrm{o}} \tau\right)\right]
$$

at the time instant

$$
t_{\mathrm{sc}, \max }=\frac{\arctan \left(\omega_{\mathrm{o}} \tau\right)}{\omega_{\mathrm{o}}} .
$$

Regarding the semiconductors, this analytic approach is subject to the following simplifications:

- The knee voltage of the semiconductors is omitted. In reality, the switching device and the freewheeling diode have different values; thus, the inserted knee voltage would change with current 
direction. The knee voltage is relatively small compared to the total voltage drop in the RLC circuit. Therefore, it does not have a major influence for the current characteristic.

- The resistance of the semiconductor is assumed to be constant, also disregarding that switching device and free-wheeling diode have different on-state resistance values. Depending on current direction, this would change the characteristic of the damped oscillation.

The circuit simulations carried out for this paper take the mentioned points into account. Still, there are simplifications which result in differences between the simulations and a real case:

- The conduction characteristics (V-I curves) for the switching device and the free-wheeling diode are linearized, yielding a resistive part (the onstate resistance $R_{\mathrm{on}}$ ) and a constant potential (the knee voltage $V_{\mathrm{k}}$ ). Hence, the semiconductors are modeled as a series connection of ideal device, on-state resistance, and knee voltage. In reality, the resistive part changes for high currents outside of the nominal operation. IGBTs, for example, experience a strong increase in on-state resistance when saturation is reached.

- Temperature dependencies are not taken into account. It is difficult to predict the resistivity under the high currents (well beyond the nominal operation) that flow during a shoot-through fault. This is because extreme overheating might melt the metallization of the semiconductors or even the semiconductor material itself.

- Resistances of the package (contact resistance and resistance of the aluminum and other materials) are omitted.

Therefore, care should be taken when interpreting the analytical and simulation results. In the following, simulations carried out with PLECS are presented. For simplicity it is assumed that the energy of the cell dissipates entirely in the semiconductors $\mathrm{S}_{1}, \mathrm{~S}_{2}$, and $\mathrm{T}$ (i.e. $R_{\text {bus }}$ and ESR are omitted).

Table I lists the four scenarios chosen for comparison. Case 1 is a wire-bonded IGBT module and it can be expected that the wire-bonds melt early during the fault [2]. Hence, it is questionable that the real shoot-through current corresponds to the simulations presented here. Case 2-4 employ semiconductors with stable SCFM. Case 2 and case 3 use data from a currently available Stakpak BIGT and a press-pack IGCT. Both are reverse conducting, i.e. the diode is integrated. The maximum permitted half-sine current surge for both devices is a $10 \mathrm{~ms}$ pulse with a peak current of $32 \mathrm{kA}$. Data for the theoretical SiC GTO and diode (case 4) is generated from the formulae given in [10] and [11] respectively.

The capacitance is calculated for a cell in a modular multilevel converter with the formula derived in [12]. It is proportional to the power rating of the converter and inversely proportional to the cell voltage. Said differently, for increased cell voltage the capacitance decreases by the same factor. This means that in a converter with given power rating and dc voltage, the stored energy in one cell is proportional to the cell voltage. For increased cell voltage the amount of cells required per arm decreases; thus, the energy stored in the whole converter stays the same. For an MMC with $1 \mathrm{GW}$ transmission power and $\pm 320 \mathrm{kV}$ dc-side voltage, this yields the capacitance values given in Table I. The parasitic inductance of the IGBT cell was assumed to be $200 \mathrm{nH}$. For the IGCT implementations $L_{\mathrm{di} / \mathrm{dt}}$ was calculated to limit the current slope to $1000 \mathrm{~A} / \mu \mathrm{s}$.

TABLE I. Shoot-THRoUgh SIMULATION CASES

\begin{tabular}{c|cccc} 
Case & 1 & 2 & 3 & 4 \\
\hline Semiconductor & IGBT & BIGT & RC-IGCT & SiC GTO ** \\
& {$[13]$} & {$[14]$} & {$[15]$} & {$[10][11]$} \\
Package & WBM & StakPak & Press-pack & - \\
Surge current & - & $32 \mathrm{kA}$ & $32 \mathrm{kA}$ & - \\
& & $10 \mathrm{~ms}$ & $10 \mathrm{~ms}$ & \\
$R_{\text {on }, s w[\mathrm{~m} \Omega]}$ & 1.1 & 0.45 & 0.43 & 0.54 \\
$R_{\text {on }, d}[\mathrm{~m} \Omega]$ & 0.87 & 0.27 & 0.96 & 0.36 \\
$V_{k, s w}[\mathrm{~V}]$ & 1.45 & 1.8 & 1.7 & 4.08 \\
$V_{k, d}[\mathrm{~V}]$ & 1 & 1.75 & 2.4 & 3.68 \\
\hline$L[\mu \mathrm{H}]$ & $0.2 *$ & $0.2 *$ & 2.25 & 16.5 \\
$V_{C}[\mathrm{kV}]$ & 1.65 & 2.25 & 2.25 & 16.5 \\
$C[\mathrm{mF}]$ & 12.26 & 8.99 & 8.99 & 1.23 \\
$E_{t o t}[\mathrm{~kJ}]$ & 16.7 & 22.8 & 22.8 & 167 \\
\hline \multicolumn{5}{c}{$*$ parasitic inductance } \\
& $* *$ theoretical
\end{tabular}

Fig. 2 illustrates the shoot-through currents for the cases listed in Table I. The converter cells with only parasitic inductance experience a current peak of $280 \mathrm{kA}$ for case 1 and $416 \mathrm{kA}$ for case 2 . Both cells have dissipated their entire energy after approximately $1 \mathrm{~ms}$. The maximum current for the cells employing di/dt limiting reactors is lower, around $140 \mathrm{kA} . L_{\mathrm{di} / \mathrm{dt}}$ is an inherent protection against high peak currents, but can also be designed to limit the maximum shoot-through current to a desired value at the cost of introducing additional switching losses (when $\mathrm{S}_{1}$ switches off a positive current, the remaining energy in $L_{\mathrm{di} / \mathrm{dt}}$ is dissipated in the RCD circuit). Case 3 and 4 experience a similar shoot-through current, although the total energy in the cells is very different. This is because $L_{\mathrm{di} / \mathrm{dt}}$ is designed according to nominal cell voltage $V_{C}$. Since the semiconductor characteristics are both similar, case 3 is more damped than case 4 . This also becomes clear when determining $\tau$ (5) for both cases. All shown cases exceed the permitted surge currents for these devices.

\section{DISSIPATION LOOP}

To handle the issues described in the last section, converter cells have to be discharged safely, while still providing a path for the converter arm current. In case of a cell employing wire-bonded IGBT modules (in explosionproof housing), the cell has to be bypassed externally as fast as possible. To bypass the cell for continued operation, a mechanical bypass switch $S_{m}$ is attached to the cell terminals, as indicated in Fig. 1 (a). For press-pack IGCT cells there are no internal open circuits. 


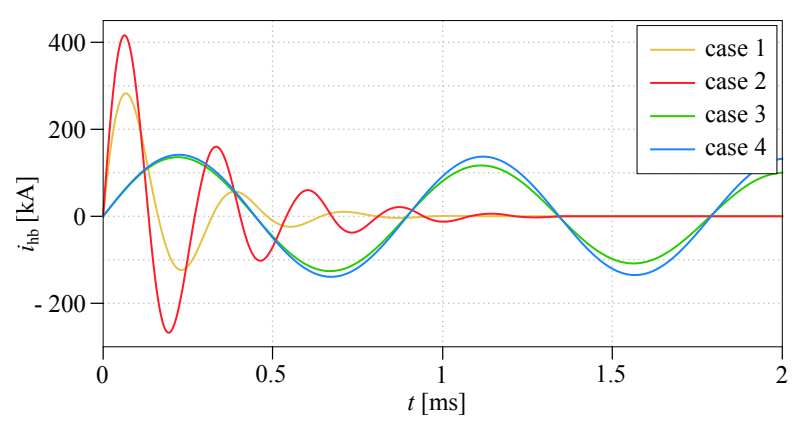

Fig. 2. Shoot-through current for the four cases listed in Table I.

Therefore, a path for the arm current is always available. To distribute the dissipated energy, a bypass thyristor can be arranged in parallel to the half-bridge, as shown in Fig. 1 (b). In a shoot-through fault this thyristor would take over the current (or at least a large share of the current). The capacitor is then discharging through the thyristor. Current will flow through the cell capacitors until all energy is dissipated.

In this paper, we propose to dissipate the cellcapacitor energy in a dedicated dissipation loop (DL). The loop is formed by the di/dt reactor $L_{\mathrm{di} / \mathrm{dt}}$ and a bypass thyristor $\mathrm{T}$ across it, as depicted in Fig. 1 (c). The thyristor is arranged in opposite direction to the initial shoot-through current flow.

The currents and voltages for the uncontrolled case and the proposed DL are shown in Fig. 3. When a shootthrough fault occurs, the stored energy will oscillate from $C$ to $L_{\mathrm{di} / \mathrm{dt}}$. The thyristor $\mathrm{T}$ is reverse-biased until this point. The current path is shown in Fig. 4 (a). When the current reaches its maximum (after approximately $1 / 4$ oscillation period) the remaining total cell energy is stored entirely in $L_{\mathrm{di} / \mathrm{dt}}$. The voltage $V_{\mathrm{C}}$ has its zero crossing at this point and is about to become negative. Therefore, the thyristor $\mathrm{T}$ is now forward-biased. $\mathrm{T}$ is fired and the current commutates from the half-bridge to the DL. Parasitic inductances within the circuit limit the speed of this commutation slightly. The current is now circulating in the DL, as depicted in Fig. 3 (b). As soon as $\mathrm{T}$ is triggered, there is no zero crossing of the current through the thyristor. The current in the DL will persist until the stored energy is entirely dissipated. $\mathrm{S}_{2}$ is now permanently turned on (or in a stable SCFM, if destroyed), bypassing the cell.

The instant of triggering the thyristor $\mathrm{T}$ has to be chosen carefully. Triggering within the first quarter of the oscillation period will not have any effect, since the thyristor is reverse-biased. This also means that early triggering is not an issue for the functionality of the DL. On the other hand, triggering the thyristor too late, while $C$ is charged negatively (significantly after the instant described above), should be avoided at all cost. The shoot-through current in negative direction is not limited anymore by $L_{\mathrm{di} / \mathrm{dt}}$ (only by the parasitic inductance); thus, it results in high reverse current peaks. The DL can take over the current at any of the maxima, meaning that it can be decided how much energy is dissipated in the (a)

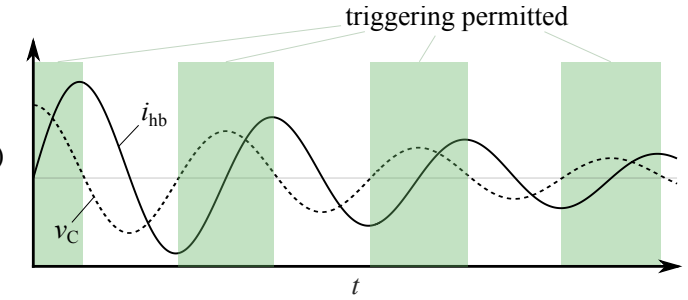

(b)

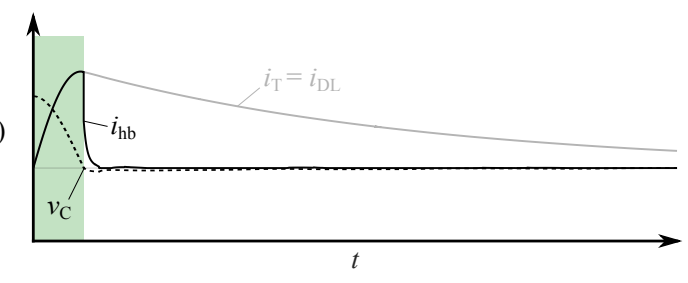

Fig. 3. Comparison of voltages and currents in the cell for uncontrolled shoot-through (a) and the proposed discharge loop mechanism (b).

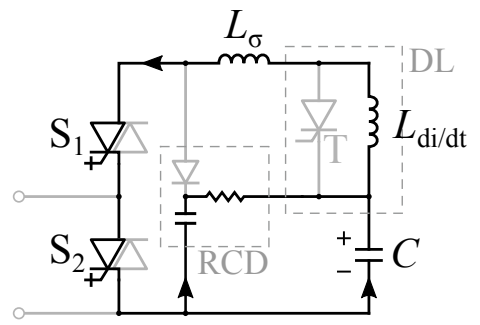

(a)

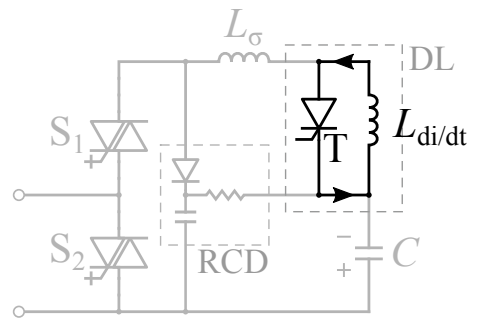

(b)

Fig. 4. Current path during shoot-through fault before (a) and after the thyristor $\mathrm{T}$ takes over the current (b).

half-bridge before the DL is fired. This will be discussed in more detail in the Section IV. The permitted intervals for triggering the thyristor of the DL are marked in Fig. 3.

With the previously described method, a fraction of the energy dissipation is shifted to the DL. The distribution of the energy among $\mathrm{S}_{1}, \mathrm{~S}_{2}$, and $\mathrm{T}$ depends on the characteristic of the oscillation and the trigger instant. Highly damped shoot-through faults (large semiconductor on-state resistance) dissipate a large share of the total energy during the first half-wave. Thus, the DL can only dissipate a smaller fraction of the total energy. For cells with a low damped RLC characteristic (low on-state resistance of the semiconductors), the majority of the energy can be dissipated in the DL. This might be interesting for future cells employing $\mathrm{SiC}$ bipolar semiconductors with blocking voltages beyond $15 \mathrm{kV}$. These devices are foreseen to have comparably low on-state resistance [10].

For the shown example of a $2.25 \mathrm{kV}$ cell (case 3) $92 \%$ of the total energy is dissipated in the DL, when 
triggering at the first current maximum. By using the same triggering instant for the $16.5 \mathrm{kV}$ cell (case 4 ), $99 \%$ of the total energy is dissipated in the DL. The DL has to be designed mechanically and thermally robust to withstand the high forces and temperatures. The advantage of the proposed solution is that these high requirements for thermal robustness apply only to a very small part of the cell, namely $L_{\mathrm{di} / \mathrm{dt}}$ and T.

The DL can be employed in any cell topology and for any semiconductor device technology with SCFM. However, the DL makes most sense for cell designs that already have a dedicated inductor, e.g. cells with thyristorbased semiconductors.

\section{ENERGY DISSIPATION}

The energy dissipation in the semiconductors is determined by their conduction characteristic (V-I curve). Switching instants are either at zero current or zero voltage. Therefore, switching losses can be disregarded. For the sake of simplicity, the V-I curve is linearized, yielding a resistive part $R_{\text {on }}$ and the knee voltage of the semiconductor $V_{\mathrm{k}}$. The instantaneous losses are determined by

$$
p_{\mathrm{l}}=R_{\mathrm{on}} i_{\mathrm{hb}}^{2}+V_{\mathrm{t}} i_{\mathrm{hb}} .
$$

Integration yields the dissipated energy of the switching device and the diode, shown in Fig. 5 (middle).

$$
e_{1}=\int_{0}^{t} p_{1} d t
$$

Since $S_{1}$ and $S_{2}$ are exposed to the same current (neglecting the arm current, which superposes in $\mathrm{S}_{2}$ ) their energy dissipation can be assumed to be equal. Thus, the total dissipated energy in the cell is determined by

$$
e_{\mathrm{dis}}=2 \int_{0}^{t}\left(p_{1, \mathrm{~S} 1}+p_{\mathrm{l}, \mathrm{D} 1}\right) d t .
$$

In Fig. 5, the shoot-through current (top), the absolute value of the dissipated energy in one press-pack (middle), and the relative value of the dissipated energy for the whole cell (bottom) is shown. The first three possible trigger instants for the DL are denoted $t_{1}, t_{2}$, and $t_{3}$. Adding up the energy of the switching device and the free-wheeling diode amounts to the dissipated energy for the semiconductor in one press-pack (marked in Fig. 5 (middle) for $t_{1}, t_{2}$, and $t_{3}$ ). In both cases a similar amount of energy is dissipated during the first few oscillations. As discussed in Section II, the oscillation for case 3 is much more damped than for case 4 . Therefore, the total cell energy is dissipated much faster for case 3 , as seen in Fig. 5 (bottom).

As mentioned before, it can be decided to trigger the thyristor at any current maximum. This might be interesting for distributing the dissipated energy among the semiconductors in the cell. The energy dissipated in the half-bridge can be tailored to what the press-packs can withstand. At the time instants $t_{1}, t_{2}$, and $t_{3}$, the energy in the cell is dissipated by $8.3 \%, 48 \%$, and $70.7 \%$ for case 3 . For case 4 it is $1.5 \%, 6.5 \%$, and $11.3 \%$ for the

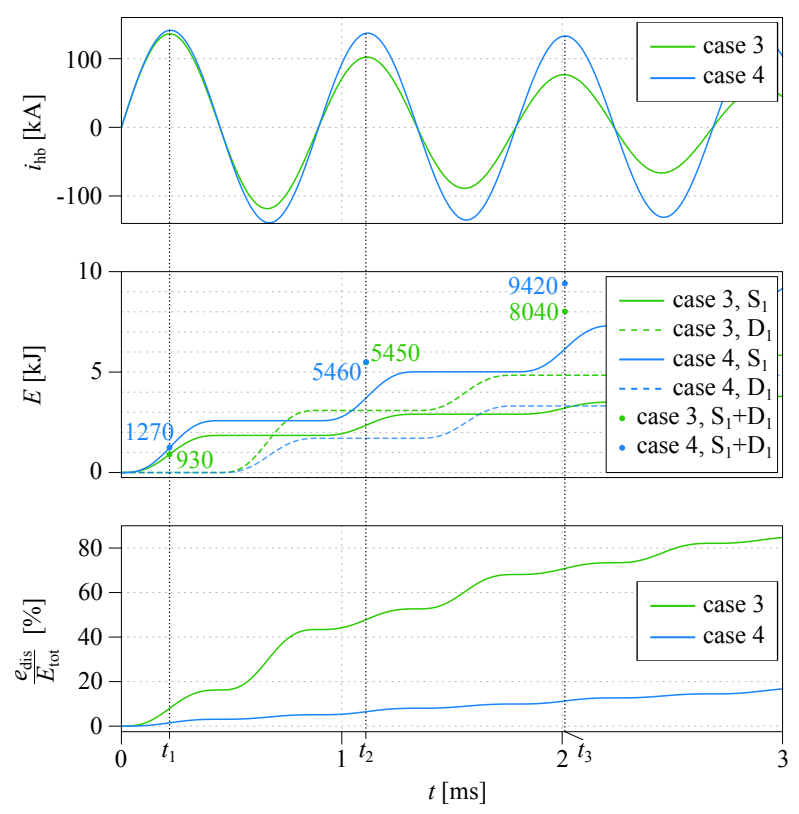

Fig. 5. Comparison of case 3 and 4: Shoot-through current (top), dissipated energy in the press-pack (middle), and relative value of the dissipated energy for the whole cell (bottom).

same time instants. Consequently, the DL has to dissipate the remaining share, after the thyristor is fired. Fig. 6 shows the shoot-through current in the half-bridge for case 3 for the first five possible trigger instants.

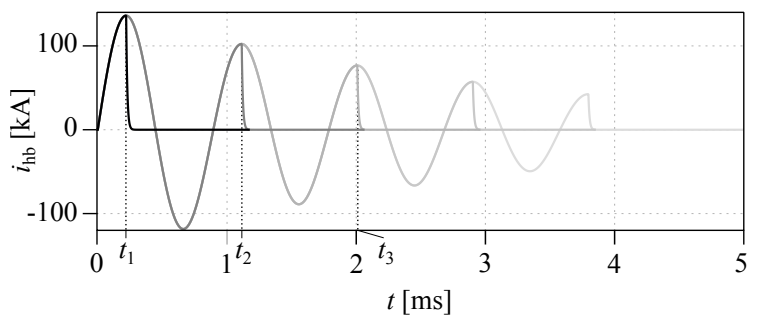

Fig. 6. Simulation of current through half-bridge (case 3) with the DL taking over the shoot-through at different maxima.

It is difficult to predict the consequences of the high current during shoot-through for the circuit. The DL itself has to be built in an extremely robust way. Depending on the characteristic of the bypass thyristor for these high currents beyond $100 \mathrm{kA}$ (including its behavior when materials heat up and melt), the energy dissipation is shared between the parasitic resistance of the inductor and the thyristor press-pack itself. For the semiconductor devices in the half-bridge, simplified predictions about the temperature can be made by assuming adiabatic heating of the materials in the press-pack. The temperature increase for a certain amount of dissipated energy can then be determined by using

$$
\Delta T=\frac{E}{c_{\mathrm{p}} m},
$$

where $c_{\mathrm{p}}$ is the specific heat and $m$ the mass of the absorbing medium. As indicated in Fig. 7, the three main materials in the heat conduction path are the semiconductor itself ( $\mathrm{Si}$ or $\mathrm{SiC}$ ), the molybdenum (Mo) discs (utilized 
as intermediate contact material), and the aluminum (Al) package. The material constants are given in Table II and the calculated temperature increase $\Delta T$ is given in Table III. The absolute values given in Fig. 5 (middle) serve as input for the temperature calculation. For calculating $\Delta T$, we assume that the dissipated energy is entirely contained in one of these elements (e.g. if $5450 \mathrm{~J}$ would be dissipated entirely in the molybdenum discs, they would heat up by $150 \mathrm{~K}$ ). Thus, the calculations are kept simple, at the cost of slightly overestimating the temperatures. In reality, the semiconductor itself heats up most, but some of the heat is transferred to the adjacent molybdenum discs before the maximum temperature has been reached. The molybdenum discs transfer the heat to the aluminum plates, which form the top and bottom layer of the presspack. The heat transfer is slow, so it can be expected that the real temperature for the $\mathrm{Si}$ or $\mathrm{SiC}$ wafers is close to the calculated value. The temperature at the surface of the press-pack is of major interest, since the surfaces are attached to a heatsink. The coolant of the heatsink should be able to handle the temperature increase.

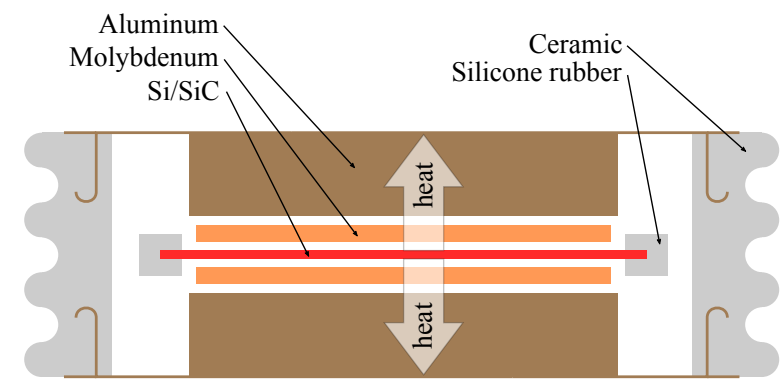

Fig. 7. Simplified cross section of a press-pack device.

TABLE II. MATERIAL CONSTANTS FOR THE MAIN COMPONENTS OF A PRESS-PACK

\begin{tabular}{c|cccc} 
Material & $\mathrm{Si}$ & $\mathrm{SiC}$ & $\mathrm{Mo}$ & $\mathrm{Al}$ \\
\hline melting temp. [K] & 1687 & 3100 & 2896 & 660 \\
spec. heat $[\mathrm{J} / \mathrm{kg} \mathrm{K}]$ & 700 & 690 & 277 & 921 \\
density $[\mathrm{kg} / \mathrm{m} 3]$ & 2330 & 3210 & 10280 & 2699 \\
volume $[\mathrm{m} 3]$ & $3.18 \mathrm{e}-6 *$ & $3.18 \mathrm{e}-6^{*}$ & $1.27 \mathrm{e}-5 * *$ & $1.27 \mathrm{e}-4 * * *$ \\
\hline & $* \varnothing 90 \mathrm{~mm}$ wafer, $500 \mu \mathrm{m}$ thickness \\
& $* *$ two $\varnothing 90 \mathrm{~mm}$ plates, $1 \mathrm{~mm}$ thickness \\
& $* * *$ two $\varnothing 90 \mathrm{~mm}$ plates, $1 \mathrm{~cm}$ thickness
\end{tabular}

TABLE III. TEMPERATURE INCREASE FOR THE MATERIALS IN THE PRESS-PACK IN KELVIN

\begin{tabular}{ccc|cccc} 
case & $t$ & $e_{\text {dis }}[\mathrm{J}]$ & $\Delta T_{S i}$ & $\Delta T_{S i C}$ & $\Delta T_{M o}$ & $\Delta T_{A l}$ \\
\hline 3 & $t_{1}$ & 930 & 179 & 132 & 26 & 3 \\
3 & $t_{2}$ & 5450 & 1051 & 774 & 150 & 17 \\
3 & $t_{3}$ & 8040 & 1550 & 1141 & 222 & 25 \\
\hline 4 & $t_{1}$ & 1270 & 245 & 180 & 35 & 4 \\
4 & $t_{2}$ & 5460 & 1052 & 775 & 151 & 17 \\
4 & $t_{3}$ & 9420 & 1816 & 1337 & 260 & 30 \\
\hline
\end{tabular}

It becomes evident that even for triggering the DL at the first current maximum, the semiconductors in the half-bridge reach temperatures outside of their rating. It can be expected that the semiconductor metallization melts down first, since $\mathrm{Si}$ and $\mathrm{SiC}$ have higher melting temperatures. The temperatures at the case of the presspack seem uncritical, even when triggering at the third current maximum. The authors do not doubt that this kind of stresses can be handled by the press-pack. Shootthrough tests on IGCTs have already been performed with over $60 \mathrm{~kJ}$ of energy stored in the capacitor [3]. After a shoot-through, the SCFM was confirmed by subjecting the IGCTs to rated currents for 15 hours. The resistance of the press-packs in SCFM was around $2 \mathrm{Vrms}$ for the duration of the test.

\section{CONCLUSION}

This paper proposes a discharge loop to handle shootthrough faults in converter cells employing thyristorbased semiconductors, e.g. IGCTs. The dissipation loop, formed by the inherently needed di/dt limiting reactor and a bypass thyristor, can be utilized to relieve the main circuit from electrical, mechanical, and thermal stress. Especially for cells with high stored energy and low resistance, a large portion $(>90 \%)$ of the total cell energy can be dissipated in the dedicated dissipation loop. The remaining stress on the half-bridge is within the range of what current IGCT press-packs can handle. Thus, high requirements for mechanical and thermal robustness have to be fulfilled only for the components forming the discharge loop, i.e. the di/dt limiting reactor and the bypass thyristor. A disadvantage is that the discharge loop can only be triggered at a current maximum, when the cell energy is entirely stored in the reactor. Therefore, it has to be guaranteed that semiconductor packages in the halfbridge can withstand the heat dissipation until that point. This is achieved by using devices with short-circuit failure mode.

Using the discharge loop might be interesting for future cells with a lot of stored energy. These could be cells employing $\mathrm{SiC}$ semiconductors with blocking voltages of $15 \mathrm{kV}$ and higher.

\section{ACKNOWLEDGEMENT}

The authors would like to acknowledge SweGRIDS for funding this project and ABB Corporate Research Center (SECRC) for their valuable support.

\section{REFERENCES}

[1] D. Cottet et al., "Integration technologies for a medium voltage modular multi-level converter with hot swap capability," in 2015 IEEE Energy Conversion Congress and Exposition (ECCE), Sep 2015, pp. 4502-4509.

[2] M. Billmann, D. Malipaard, and H. Gambach, "Explosion proof housings for IGBT module based high power inverters in HVDC transmission application," in Proc. PCIM Eur. 2009 Conf., Nuremberg, May 2009, pp. 352-357.

[3] F. Dijkhuizen and S. Norrga, "Fault tolerant operation of power converter with cascaded cells," in Proceedings of the 2011 14th European Conference on Power Electronics and Applications, Aug 2011.

[4] P. Ladoux, N. Serbia, and E. I. Carroll, "On the potential of IGCTs in HVDC," IEEE Journal of Emerging and Selected Topics in Power Electronics, vol. 3, no. 3, pp. 780-793, Sep 2015.

[5] T. Modeer, H. P. Nee, and S. Norrga, "Loss comparison of different sub-module implementations for modular multilevel converters in HVDC applications," in Proceedings of the 2011 14th European Conference on Power Electronics and Applications, Aug 2011, pp. 1-7. 
[6] T. Modeer, S. Norrga, and H.-P. Nee, "Implementation and testing of high-power IGCT-based cascaded-converter cells," in 2014 IEEE Energy Conversion Congress and Exposition (ECCE), Sep 2014, pp. 5355-5359.

[7] H.-G. Eckel and H. Gambach, "Double module for a modular multi-stage converter (US 9263969 B2)," 2016.

[8] C. Dahmen and R. Marquardt, "Progress of High Power Multilevel Converters: Combining Silicon and Silicon Carbide," in PCIM Europe 2017; International Exhibition and Conference for Power Electronics, Intelligent Motion, Renewable Energy and Energy Management, May 2017.

[9] K. Jacobs, D. Johannesson, S. Norrga, and H. P. Nee, "MMC converter cells employing ultrahigh-voltage $\mathrm{SiC}$ bipolar power semiconductors," in 2017 19th European Conference on Power Electronics and Applications (EPE'17 ECCE Europe), Sep 2017.

[10] D. Johannesson, M. Nawaz, K. Jacobs, S. Norrga, and H. P. Nee, "Potential of ultra-high voltage silicon carbide semiconductor devices," in 2016 IEEE 4th Workshop on Wide Bandgap Power Devices and Applications (WiPDA), Nov 2016, pp. 253-258.

[11] N. Kaji, H. Niwa, J. Suda, and T. Kimoto, "Ultrahigh-voltage SiC p-i-n diodes with improved forward characteristics," IEEE Transactions on Electron Devices, vol. 62, no. 2, pp. 374-381, Feb 2015.

[12] M. M. C. Merlin and T. C. Green, "Cell capacitor sizing in multilevel converters: cases of the modular multilevel converter and alternate arm converter," IET Power Electronics, vol. 8, no. 3, pp. 350-360, Mar 2015.

[13] Mitsubishi, "CM1500HC-66R data sheet, High Voltage Insulated Gate Bipolar Transistor Modules," Dec 2012.

[14] ABB, "5SJA 3000L450300 data sheet, StakPak BIGT Module PRELIMINARY," Mar 2017.

[15] ABB., "5SHX 26L4520 data sheet, Reverse Conducting Integrated Gate-Commutated Thyristor," Apr 2016. 